\title{
USO DE ESTUFA COM COBERTURA PLÁSTICA E DE QUEBRA-VENTOS NA PRODUÇÃO DE PORTA-ENXERTOS DE SERINGUEIRA ${ }^{1}$
}

\author{
J.E.M. PEZZOPANE²; M.J. PEDRO Jr.,4; A.A. ORTOLANI ${ }^{3,4}$ \\ ${ }^{2}$ Centro Agropecuário-UFES, C.P. 16, CEP: 29.500-000, Alegre, ES. \\ ${ }^{3}$ Sę̧ão de Climatologia Agrícola/IAC, C.P. 28, CEP: 13001-970, Campinas, SP. \\ Bolsista do CNPq.
}

RESUMO: $O$ experimento foi realizado com o objetivo de estudar o efeito de dois tipos de ambiente parcialmente protegidos: estufa coberta com polietileno transparente de baixa densidade (PEBD) e quebra-ventos construído com tela plástica, no crescimento de porta-enxertos de seringueira, durante o inverno na região de Campinas-SP. A fim de analisar o crescimento dos porta-enxertos, foram medidos: diâmetro, altura, área foliar e peso seco. Os resultados obtidos na condição experimental, mostraram que as plantas protegidas pelo quebra-rentos não apresentaram uma diferença significativa no crescimento em relação a testemumha, mas que o uso da estufa provocou um incremento em diâmetro $(60 \%)$, altura $(108 \%)$, área foliar $(266 \%)$ e peso da matéria seca $(286 \%)$ dos porta-enxertos. Após seis meses, admitindo um diâmetro mínimo de $8 \mathrm{~mm}$ para realizar a enxertia verde, $60 \%$ dos porta-enxertos conduxidos no interior da estufa já estavam aptos a enxertia, enquanto que nos outros dois tratamentos, nenhuma planta atingiu o diâmetro mínimo.

Descritores: Porta-enxerto de seringueira, estufa, quebra-ventos

\section{USE OF TRANSPARENT POLYETHYLENE GREENHOUSE AND WINDBREAKS TO PRODUCE RUBBER-TREE ROOTSTOCKS}

ABSTRACT: A field experiment was carried out in order to study the effect of two kinds of parcially protected environments: greenhouse cover with transparent polyethylene of low density and plastic screan windbreaks, to grow rubber-tree rootstocks, during the winter season in Campinas, SP, Brazil. Diameter, height, leaf area, and dry weight of young rubber plants were mensured, and results showed that protected plants by windbreaks did not present significant differences during the initial growing stage, in relation to the non protected ones. The use of greenhouse, however, caused increments in diameter $(60 \%)$, height $(108 \%)$, leaf area $(266 \%)$, and dry weight $\mathbf{2 8 6 \% )}$ of the rootstocks. Atfer six months, considering that a minimum diameter of $8 \mathrm{~mm}$ is needed to perform green budding, $60 \%$ of rootstocks conducted inside the greenhouse were in condition to be budded, while in the two other treatments, the plants did not reach the minimum diameter.

Key Words: rubber rootstock, greenhouse, windbreak

\section{INTRODUÇÃO}

$\mathrm{Na}$ região sudeste do $\mathrm{Brasil}$, onde ainda são utilizadas tecnologias geradas na região tradicional de cultivo da seringueira, o tempo para produzir porta-enxertos aptos à enxertia madura (convencional) varia de 18 a 24 meses (PEREIRA, 1987).

Esse longo tempo de permanência das mudas nos viveiros, em algumas regióes do Estado de São Paulo, é devido às condições climáticas não favoráveis ao crescimento durante o inverno, em virtude da queda das sementes da seringueira ocorrer entre os meses de fevereiro e abril. De acordo com ORTOLANI (1992) este problema é mais frequente em regiões de maior altitude e localidades situadas ao sul e sudoeste do Estado, podendo, contudo, ocorrer em outras regiões, como o Planalto Ocidental.

O uso de outras técnicas de propagação onde a enxertia possa ser realizada mais rapidamente, como é o caso da enxertia verde, juntamente com um controle das condições ambientais é desejável, pois, podem tornar mais econômico o sistema de produção de mudas no Estado de São Paulo.

Produzindo mudas de seringueira em duas épocas diferentes (inverno e verão), na região de Piracicaba-SP, ROCHA NETO (1990) verificou um crescimento mais lento durante o inverno, 
constatanto uma forte influência da temperatura e umidade do ar, radiação solar e do vento sobre o crescimento das plantas, quando levado em conta o tempo necessário para a formação de mudas aptas ao plantio no campo. Segundo o autor, no inverno as condições climáticas estressantes comprometeram a utilização do nitrogenio pelas plantas, afetando a síntese de proteína. Além disso, no verão o curso diário do comportamento de abertura e fechamento dos estômatos foi favorecido, permitindo maior eficiência fotossintetica.

HUA-SON (1983), trabalhando na China, observou um crescimento lento de plantas jovens de seringueira no período de inverno, quando as temperaturas são baixas e a precipitação é reduzida. PEREIRA et al. (1985), trabalhando em Lavras, MG, também verificaram um crescimento reduzido de porta-enxertos de seringueira durante o inverno, principalmente quando a média mensal das temperaturas mínimas foi menor que $15^{\circ} \mathrm{C}$ e a temperatura média mensal foi menor que $20^{\circ} \mathrm{C}$.

$\mathrm{Na}$ obtenção de brotos para a minienxertia, em condições de campo, LEMOS FILHO (1991) observou que quando a temperatura média do ar se manteve abaixo de $19^{\circ} \mathrm{C}$, ocorreu um grande atraso na iniciação e crescimento das brotações do clone RRIM-600. O autor, utilizando o método de ARNOLD (1959), encontrou uma temperatura base inferior $(\mathrm{Tb})$ igual a $16.0^{\circ} \mathrm{C}$, pois temperaturas inferiores a fetam as atividades fisiologicas, que resultam em um comprometimento do lançamento de novos fluxos foliares.

De acordo com ORTOLANI (1986) a seringueira tem como temperatura ideal para crescimento valores entre 27 e $30^{\circ} \mathrm{C}$, e quando ocorrem valores superiores a $40^{\circ} \mathrm{C}$, a taxa de respiração excede a de fotossíntese. Ainda, segundo o autor, temperaturas médias do ar abaixo de $18^{\circ} \mathrm{C}$ são críticas para o crescimento, e quando inferiores à $15^{\circ} \mathrm{C}$, inibem a diferenciação dos tecidos.

Considerando o exposto, foi desenvolvido este trabalho com o objetivo de analisar o efeito de dois tipos de ambiente parcialmente protegidos: estufa coberta com polietileno transparente de baixa densidade (PEBD) e quebra-ventos construído com tela de polietileno no crescimento de porta-enxertos de seringueira durante 0 inverno, na região de Campinas,SP.

\section{MATERIAL E MÉTODOS}

O experimento foi conduzido no Centro Experimental de Campinas do Instituto Agronômico (latitude: $22^{\circ} 54^{\prime} \mathrm{S}$, longitude: $47^{\circ} 05^{\prime} \mathrm{W}$ e altitude:
$669 \mathrm{~m}$ ). Segundo a classificação de Kōppen, o clima da região é Cwa, subtropical úmido com inverno seco.

0 experimento foi iniciado em abril de 1993, com a coleta de sementes, e terminado em novembro do mesmo ano.

Foram formados tres canteiros com quatro linhas de 7,0 m, sendo as linhas espaçadas de 1,0 m. Como cada linha continha cerca de 50 mudas ensacoladas, o canteiro comportou cerca de 200 mudas. A área de cada canteiro foi de cerca de 25 $\mathrm{m}^{2}$. O processo de formação dos porta-enxertos deu-se da maneira recomendada por PEREIRA (1986).

Dos tres canteiros, um foi conduzido dentro de uma estufa com cobertura plástica, o outro foi protegido por um quebra-ventos e o terceiro foi conduzido sem proteção (testemunha).

Foi construída uma estufa com telhado em arco, como descrita por ROBLEDO DE PEDRO \& VICENTE (1988) e SGANZERLA (1986), com $10 \mathrm{~m}$ de comprimento, $5 \mathrm{~m}$ de largura, lateral com $1,8 \mathrm{~m}$ de altura e telhado de $1,3 \mathrm{~m}$ de altura, totalizando $3,1 \mathrm{~m}$ de altura máxima. Como cobertura foi utilizado um filme de polietileno de baixa densidade aditivado, com espessura de 0,1 mm. As laterais foram fechadas com o mesmo material, mas com espessura de $0,05 \mathrm{~mm}$.

0 quebra-ventos foi construído com tela plástica com porosidade de 50\%, recomendada por ROBLEDO DE PEDRO e VICENTE (1988), com altura de $1,7 \mathrm{~m}$ e comprimento de $6,0 \mathrm{~m}$. Foi instalado perpendicularmente d̀s linhas do canteiro a uma distância de $1,5 \mathrm{~m}$.

$\mathrm{Na}$ avaliação do crescimento em diâmetro e altura e número de lançamentos, foram utilizadas 35 plantas localizadas na parte central de cada canteiro. Para a determinação da área foliar e do peso da materia seca, foram sorteadas 15 plantas dentre as citadas anteriormente. $O$ crescimento dos porta-enxertos foi comparado entre os tratamentos através da "análise de intervalos de confiança", proposto por SNEDECOR \& COCHRAW (1973).

No centro de cada canteiro, dentro de um microabrigo instalado a $0,5 \mathrm{~m}$ de altura, foi colocado um termómetro de resistencia de platina, possibilitando assim a determinação da temperatura do ar máxima e mínima diárias. Os dados de temperatura do ar também foram comparados através da "analise de intervalos de confiança".

Utilizando os dados díarios de temperatura do ar máxima e mínima determinou-se o total de graus-dia, de acordo VILLA NOVA et al. (1972), 
TABELA 1 - Valores médios e resultado da análise estatística de intervalos de confiança, do crescimento em diâmetro, altura, área foliar, distância média entre lançamentos e peso da matéria seca.

\begin{tabular}{|c|c|c|c|}
\hline & Testemunha & Quebraventos & Estufa \\
\hline Diâmetro (mm) & $5,3 \underline{a}$ & $5,5 \underline{a}$ & $8,4 \underline{b}$ \\
\hline Altura (cm) & $35 \underline{a}$ & $39 \underline{a}$ & $73 \underline{\underline{b}}$ \\
\hline Área foliar $\left(\mathrm{cm}^{2}\right)$ & $624 \underline{a}$ & $621 \underline{a}$ & $2.283 \underline{b}$ \\
\hline $\begin{array}{l}\text { Distância média entre } \\
\text { lançamentos (cm) } \\
\text { Peso da matéria seca (g) }\end{array}$ & $11 \underline{a}$ & $12 \underline{a}$ & $18 \underline{b}$ \\
\hline - sistema radicular & $1,4 \underline{a}$ & $2,2 a$ & $5,4 \underline{b}$ \\
\hline - peso seco total & $6,9 \underline{a}$ & $8,6 \underline{a}$ & $30,3 \underline{b}$ \\
\hline
\end{tabular}

As médias seguidas de letras iguais não apresentam diferenças estatísticas.

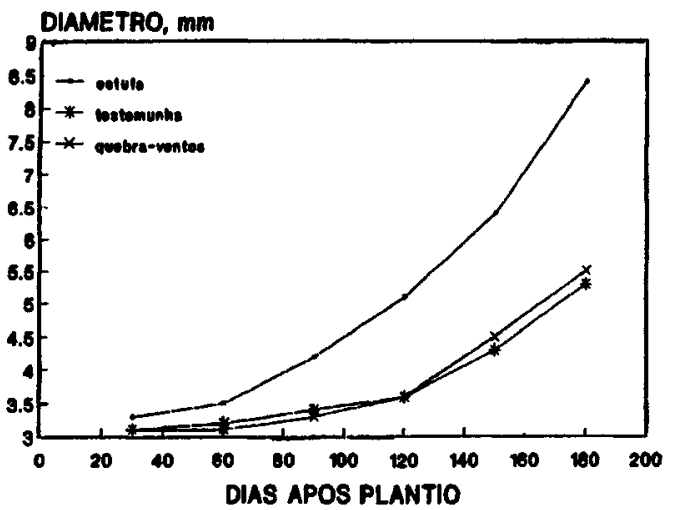

Figura 1 - Crescimento médio em diâmetro, dos porta-enxertos de seringueira submetidos aos três tratamentos: testemunha, estufa e quebra-ventos.

utilizando como base inferior a temperatura de 16 ${ }^{\circ} \mathrm{C}$, determinada por LEMOS FLHO (1991).

\section{RESULTADOS E DISCUSSÃO}

Na TABELA 1 são mostrados os valores médios e o resultado da análise estatística de intervalo de confiança do crescimento dos portaenxertos nos três tratamentos.

O diâmetro dos porta-enxertos conduzidos dentro da estufa apresentou maior crescimento em relação aos tratamentos testemunha e quebra-ventos, sendo que entre esses dois últimos, não houve diferença significativa. Admitindo um diâmetro mínimo de $8 \mathrm{~mm}$ para realizar a enxertia verde
(RRIM, 1980), 60\% das plantas monitoradas no interior da estufa já estavam aptas a enxertia, enquanto que nos outros dois tratamentos, nenhuma planta atingiu o diâmetro mínimo.

A taxa de crescimento em diametro dos porta-enxertos na estufa foi $1,4 \mathrm{~mm} / \mathrm{més} \mathrm{em} \mathrm{média,}$ enquanto na condição exterior (testemunha e quebra-ventos) a média foi $0,9 \mathrm{~mm} / \mathrm{mês}$ (Figura 1).

Com relação ao crescimento em altura, os porta-enxertos apresentaram uma taxa média de $12,0 \mathrm{~mm} / \mathrm{mês}$ na estufa, $5,8 \mathrm{~mm} / \mathrm{mês}$ no canteiro testemunha e $6,5 \mathrm{~mm} / \mathrm{mês}$ no canteiro protegido pelo quebra-ventos, resultando numa diferença significativa de crescimento entre a estufa e os demais tratamentos (Figura 2).

Além dos maiores valores no diâmetro e altura dos porta-enxertos, a estufa propiciou um aumento significativo na área foliar e peso da matéria seca, tanto do sistema radicular quanto da parte aérea. As plantas protegidas pelo quebraventos, apresentaram um pequeno incremento no peso da matéria seca (TABELA1), que não foi significativo.

A distância média entre lançamentos foi significamente maior no interior da estufa, indicando uma condição de estiolamento, porém sem acarretar em problemas, porque a razão entre peso da matéria seca da parte aérea e do sistema radicular, foi a mesma nos dois tratamentos (testemunha e estufa), e essa relação não indicou condição de estiolamento.

Vários autores tem citado a influência das condições climáticas adversas de inverno, 
TABELA 2 - Valores médios e resultado da análise estatística de intervalo de confiança, das temperaturas do ar máximas, mínimas e médias, e total de graus-dia observados nos três tratamentos.

\begin{tabular}{lccc}
\hline & Testemunha & Quebraventos & Estufa \\
\hline Temperatura máxima $\left({ }^{\circ} \mathrm{C}\right)$ & $26, \underline{2} \underline{a}$ & $26,3 \underline{a}$ & $31,8 \underline{b}$ \\
Temperatura mínima $\left({ }^{\circ} \mathrm{C}\right)$ & $13,3 \underline{a}$ & $13,3 \underline{a}$ & $14,5 \underline{a}$ \\
Temperatura média $\left({ }^{\circ} \mathrm{C}\right)$ & $19,0 \underline{a}$ & $19,0 \underline{a}$ & $21,7 \underline{b}$ \\
Graus-dia & 960 & 960 & 1442 \\
\hline \hline
\end{tabular}

As médias seguidas de letras iguais não apresentam diferença estatística.

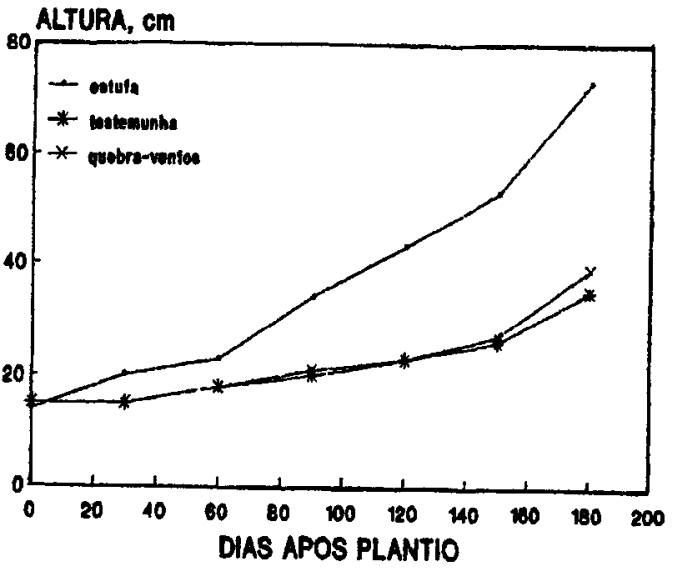

Figura 2 - Crescimento médio em altura, dos portaenxertos de seringueira submetidos aos três tratamentos: testemunha, estufa e quebra-ventos.

principalmente temperatura, no crescimento de plantas jovens de seringueira (HUA-SON, 1983; PEREIRA et al., 1985; LEMOS FILHO, 1991; MEDRADO, 1992). A atividade enzimática, assim como a velocidade das reações químicas, são processos metabólicos afetados pela temperatura, e segundo ROCHA NETO (1990), no crescimento e desenvolvimento vegetal, um metabolismo eficaz e a produção de novos tecidos são fundamentais. Além disso, a temperatura também afeta a fotossíntese, pois apesar do processo fotoquímico independer da temperatura, a fixação e a redução do $\mathrm{CO}_{2}$ aumenta proporcionalmente, até um determinado limite, com a elevação da temperatura (LACHER, 1986).
Na TABELA 2 são mostrados os valores temperatura média do ar e pode-se verificar que no interior da estufa foi, em média $2,7^{\circ} \mathrm{C}$ acima daqueles observados no canteiro testemunha. $O$ mesmo aconteceu com a temperatura máxima, que apresentou um aumento de $5,6^{\circ} \mathrm{Cna}$ média, mostrando uma eficiência térmica desse tipo de ambiente modificado. A temperatura mínima no interior da estufa não apresentou uma elevação significativa $\left(1,2^{\circ} \mathrm{C}\right)$. Ainda, ocorreu um acúmulo maior de graus-dia na estufa ao longo dos seis meses, enquanto não houve diferença entre o tratamento testemunha e o quebra-ventos.

\section{CONCLUSÕES}

Os resultados obtidos nas condições experimentais permitiram chegar as seguintes conclusões:

a) O uso da estufa com cobertura plástica propiciou um aumento de $5,6 \mathrm{e} 2,7^{\circ} \mathrm{C}$ nos valores médios de temperatura máxima e média do ar, respectivamente, mas não aumentou os valores médios de temperatura mínima do ar.

b) O uso da estufa propiciou um aumento no total de graus-dia (482), ao longo de seis meses.

c) As modificações microclimáticas causadas pela cobertura com PEBD, provocaram um incremento em diâmetro (60\%), altura (108\%), área foliar (266\%) e peso da matéria seca $(286 \%)$ nos portaenxertos de seringueira. Após seis meses, admitindo um diâmetro mínimo de $8 \mathrm{~mm}$ para realizar a enxertia verde, $60 \%$ dos porta-enxertos conduzidos no interior da estufa já estavam aptos a enxertia, enquanto que nos outros dois tratamentos, nenhuma planta atingiu o diâmetro mínimo. 
d) $O$ uso do quebra-ventos artificial não provocou mudanças significativas no crescimento dos portaenxertos de seringueira.

\section{REFERENCIAS BIBLIOGRÁFICAS}

ARNOLD, C.Y. The determination and significence of base temperature in linear heat unit system. Proceedings of the American Society for Horticultural Science, v.74, p.430-445, 1959.

HUA-SON, P. Adaptabilities of four rubber clones to higher latitude and elevations areas. Yunnan Province. In: Ptanter's Conference. Kuala Lumpur. Persidangan Pelandag, 1983. 18p.

LARCHER, W. Bcofisiologia vegetal. Trad, de A. Daneli e H.T. Buckup. São Paulo: EPU, 1986.

LEMOS FILHO, J.P. de. Aspectos fisiológicos e biometeorológicos relacionados com a técnica de minienxertia da seringueira (Hevea spp.). Campinas, 1991. 110p. (Doutorado) - Universidade Estadual de Campinas.

MEDRADO, M.J.S. Fatores relacionados to processo de propagação da seringueira (Hevea spp.), em Piracicaba,SP. Piracicaba, 1992. 178p. (Doutorado) - Escola Superior de Agricultura "Luiz de Queiroz", Universidade de Sz̃o Paulo.

ORTOLANI, A.A. Agroclimatologia e o cultivo da seringueira.In: SMMPÓSIO SOBRE A CULTURA DA SERINGUEIRA NO ESTADO DE SÃO PAULO, 1 ., Piracicaba, 1986. Anais. Campinas, Fundaçăo Cargil, 1986. p 11-32.

ORTOLANI, A.A. Limitaçð̄es climáticas para a produção de mudas de seringueira e manejo de mudas em estufas. In: Medrado, M.J.S. Formacio de mudas de seringueira. Piracicaba; ESALQ/USP, 1992.p.34 41.

PEREIRA,J.P. Formação de mudas de seringueira. In: SIMPÓSIO SOBRE A CULTURA DA SERINGUEIRA, 1, Piracicaba, 1986. Anais. Campinas: Fundaçāo Cargil, 1986. p.139-164.
PERERA, J. da P.; BUENO, N.; HAAG, H.P. Alguns problemas relacionados com a formaçăo de mudas de seringueira (Hevea spp) In: SIMPÓSIO SOBRE A CULTURA DA SERINGUEIRA, 2., Piracicaba, 1987. Annis. Piracicaba: ESALQ/USP, 1990p.

PEREIRA, A.V.; VENTORMM, N.; DAVIDE, A.C. Crescimento de porth-enxertos de seringueirn (Hevea spp) em relação a temperatura do ar nas condiçб́es de Lavras, Minas Gerais. Ciencia e Pratica, v.9, p.157$161,1985$.

ROBLEDO DE PEDRO, F.; VICENTE, L.M. Aplicacion de los plasticos en In agricultura. 2.ed. Madrid: Mundi-Prensa, 1988. 573p.

ROCHA NETO, O.G. Aspectos ecofisiológicos sazonais na produção de mudas de seringueira (Hevea spp) na região sudeste do Brasil. Efeitos de estresses ambientais sobre o crescimento. Campinas, 1990. 111 . Tese (Doutorado) - Universidade Estadual de Campinas.

RUBBER RESEARCH INSTITUTE OF MALAYSIA. Nursey Techniques for rubber plant propagation. In: Agricultural Senes Report, Malaysia, 2“ ed., 1980. 89p.

SGANZERLA, E. Nova agricultura. 2.ed. Porto Alegre: Petroquímica Triunfo, 1986. 303p.

SNEDECOR, G.W.; COCHRAW, W.G. Statistical methods. Iowa: Iowa State University, 1973. 593p.

VILLA NOVA, N.A.; PEDRO JÚNIOR, M.J.; PEREIRA, A.R.; OMETTO, J.C. Estimntiva de grausdia acumulados acima de qualquer temperatura-base em funçăo das temperaturas máximas e mínimas. Caderno de Ciencia da Terra, v.30, p.1-8, 1972.

Recebido para publicą̧ío em 09.01.95

Aceito para publicação em 26.05 .95 